\title{
Parental Influence on Primary and Secondary School Students’ Sports Participation in China*
}

\author{
Li Ning-ning, Li Sen, Qiao Yu-jiao \\ Southwest University, Chongqing, China
}

\begin{abstract}
According to national and local official reports, the health status and physical fitness of Chinese students are indeed worsening. In an attempt to promote better physical fitness and health, the Chinese government has taken a package of measures to improve school-based physical education. However, we cannot ignore the important role of family members in developing children's healthy behaviors. The central objective of this study was to investigate parental influence on primary and secondary school students' sports participation in China in more detail. To do this, questionnaires (including student version and teacher version) and semi-structured interviews were conducted in different regions of China. The results of this study reflect that students do little physical exercise at home and parental influence on students' sports participation (including parents' perception and attitude towards their children's health and sports participation; parents' role model of sports participation; parents' support and encouragement of sports participation; and communication about students' physical education between school and family) is unrealized. These results are important when considering designing more effective interventions to improve students’ physical activity levels and to influence them to foster life-long habits of physical exercise.
\end{abstract}

Keywords: students’ sports participation, parental influence, family-based physical education

\section{Introduction}

In China, students' physical fitness and health issues have drawn much attention in recent years. The health of young students relates not only to personal development and wellbeing, but also to the health of the entire nation, according to Advice on Strengthening Adolescent's Physical Education and Enhancement of Adolescent's Physical Fitness (Central Committee and the State Council, 2007). However, due to the heavy academic burdens in China's exam-oriented education system, students spend most of the day on studying. They do not have enough time to maintain the needed exercise, which leads to a decline in overall student health status and physical fitness level.

According to the reports data of the physical fitness and health surveillance of Chinese school students, jointly conducted by the General Administration of Sport, the Ministry of Education, the Health Ministry, the State Ethnic Affairs Commission, and the Ministry of Science and Technology every five years since 1985, the general level of student fitness has shown signs of improvement after a 25-year decline. However, some

\footnotetext{
* Acknowledgment: This research is funded by the Southwest University Fundamental Research Funds for the Central Universities in 2013 (Grant No.: SWU1309428).

Li Ning-ning, Ph.D. candidate, Faculty of Education, Southwest University.

Li Sen, Ph.D., professor, Faculty of Education, Southwest University.

Qiao Yu-jiao, M.A. candidate, Faculty of Education, Southwest University.
} 
conditions, such as overweight and poor eyesight, continue to increase within the target groups (see Figures 1 and 2). Official statistics showed that more and more children were suffering from overweight or obese problem. The problem of overweight was even more severe for urban children and adolescents. For example, roughly one quarter of male students in urban areas in 2010 were overweight or obese (see Figure 1). The problem of poor eyesight was far more common than we thought and the age of onset became younger. Official statistics also showed that urban students suffered a higher prevalence of vision deficiency than rural students. For example, the data in 2010 (Ministry of Education, 2010) showed that about 32.98\% of rural primary school students, $58.74 \%$ of rural secondary school students, $48.81 \%$ of urban primary school students, and $75.94 \%$ of urban secondary school students have myopia (see Figure 2). In addition, according to the local official reports of school students' physical fitness and health surveillance in 2014 (Ren, 2013; Su, 2014; Lv, 2014), the results of major health problems, such as overweight and poor eyesight, stayed pessimistic. For example, the survey conducted by the Jiangsu Education Department showed that the problems of overweight or obesity and poor eyesight were accentuated compared with the data reported in the national survey in 2010 (Lv, 2014). The research reports above reflect that the health status of Chinese students is indeed worsening.

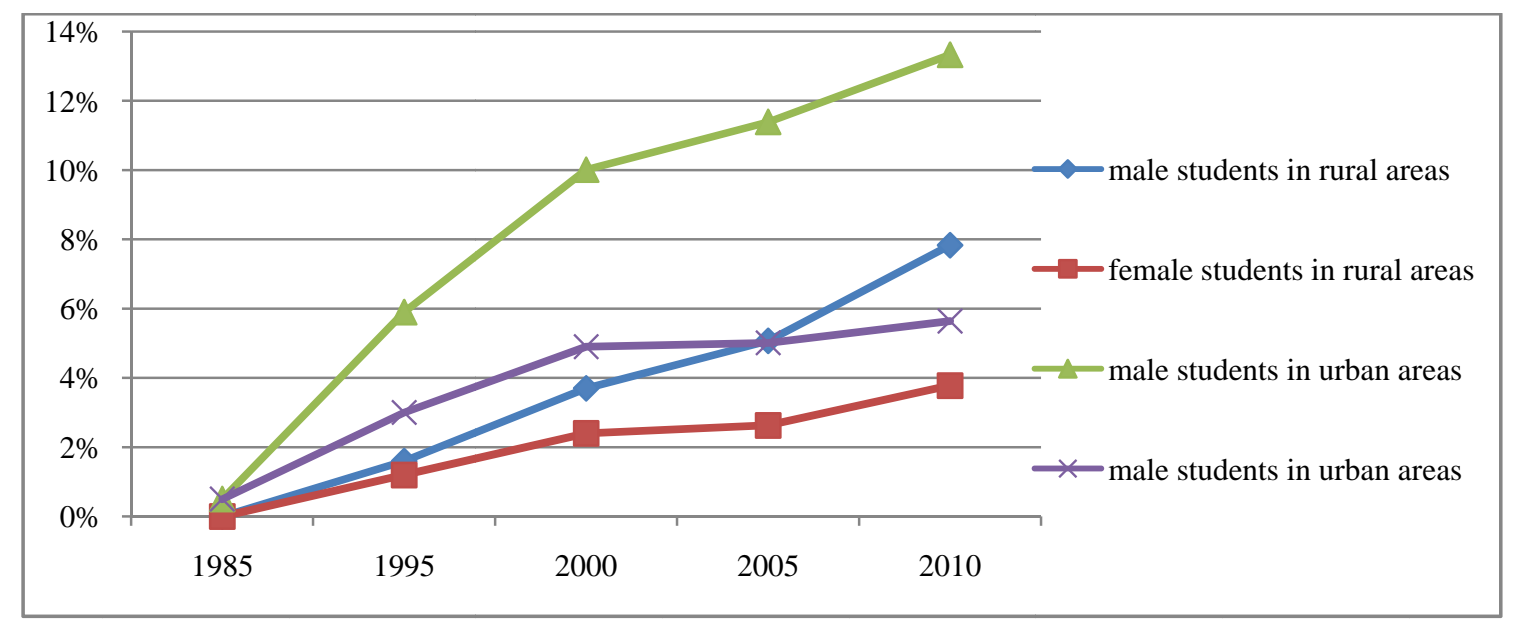

Figure 1. The change trend of the obesity rate of Chinese students from ages 7 to 22 (1985-2010).

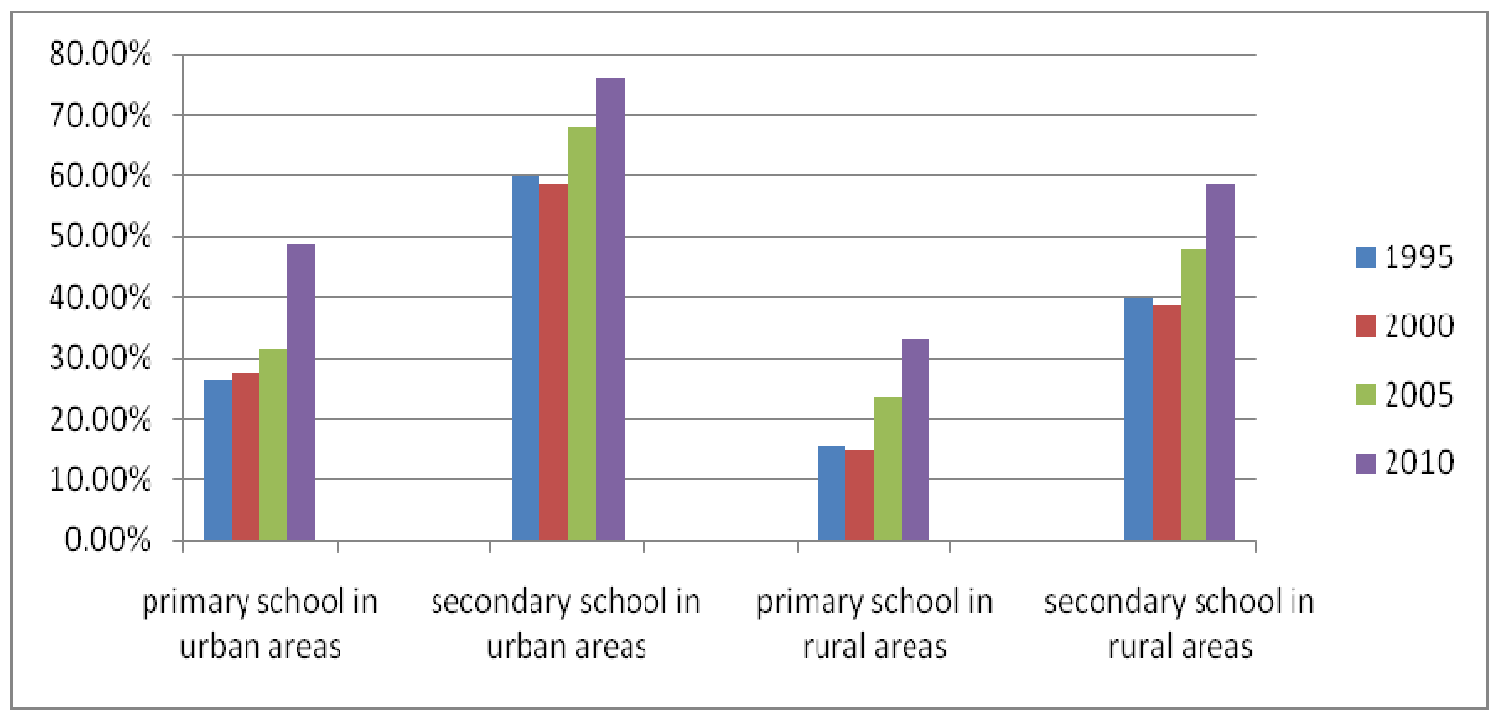

Figure 2. The change trend of the myopia rate of Chinese primary and secondary students (1995-2010). 
In an attempt to improve the worsening health status of school students, the Chinese government has taken a package of measures to improve physical education in schools. For example, a nationwide "Sunlight Sport" campaign was adopted by the central government, which guarantees that school students spend at least one hour per day on sports (Ministry of Education, General Administration of Sport, and Central Committee of the Communist Youth League, 2006). In addition, annual fitness monitoring for registered children has been carried out nationally from 2013. The Ministry of Education also announced that students' physical education performance would be related to their admission assessments and the performance evaluation of school officials. It means that local government and school leaders who fail to implement annual fitness tests or ensure enough exercise for students will be criticized publicly and removed from promotion and awards lists (Yang, 2012).

All above measures reflect that the Chinese government and education authorities are taking strengthening sports work in school very seriously indeed. And, it is obvious that school-based interventions are an important avenue for delivery of targeted health promotion initiatives in encouraging and promoting physical activity (Gortmaker et al., 1999). However, we cannot ignore the important role of family members in developing children's healthy behaviors. Parents have a significant influence on their children's sports participation, direct or indirect, intentional or unintentional (Norton, Froelicher, Waters, \& Carrieri-Kohlman, 2003; Trost, Sallis, Pate, Freedson, Taylor, \& Dowda, 2003; Kremarik, 2000; Wheeler, 2012; Timperio et al., 2013). Parents cannot pass all the responsibility of physical education to the school. In order to design more effective interventions to improve students' physical activity levels, we need to identify the parental influence on students' sports participation.

\section{Method}

This survey is the subtopic of research on students' physical fitness influences. Data collection occurred in two phases. Phase one served two purposes: (a) to gain students' fundamental information, such as age, weight, height, eyesight, and the results of physical tests; and (b) to measure students' physical fitness. In phase one, a random sample $(N=1,927)$ of student population and also a random sample $(N=585)$ of teacher population at both rural and urban primary and secondary schools in the Eastern, Middle, and Western of China, including 15 provinces, autonomous regions, and municipalities, completed a two-page survey respectively. The survey consisted of a questionnaire (including student version and teacher version) measuring students' physical fitness influences in four dimensions: the student, the school, the family, and the community. Data collection for phase two mainly involved semi-structured interviews for the students, the parents, the teachers, and the headmasters randomly selected from phase one. The survey was conducted by college students who had received training for this purpose.

Statistical analyses were carried out at Southwest University by using the Statistical Package for the Social Sciences (SPSS) Version 17.0. Descriptive statistics were used to examine students' physical fitness level and other problems concerning sports activities, such as duration, facilities, and training partners. There was no additional statistical analysis performed on the data from phase one of the study. Therefore, the interviews in phase two played a vital role in supplementing data in this study. The recordings of the interviews were transcribed into text with the notes taken by the assistants. 


\section{Results}

\section{Students' Sports Participation at Home}

According to the survey, about $39.56 \%$ of the students only spent less than half an hour on physical exercise after school on weekdays, and $38.26 \%$ of them reported that they failed to take any exercise due to heavy academic burdens. According to our interviews, most of the students stated that they had to do their homework after school and had no spare time for exercise. Some of them complained that they were often banned from leaving home after school to play or do exercise with friends. As for their weekly activities in this survey, learning and doing homework (77.2\%), watching TV and surfing the Internet (59.2\%), as well as reading (47.8\%) are the most popular activities. Only 33.1\% of the participants chose to take part in physical activity, which came to the fourth.

\section{Parental Influence on Their Children's Sports Participation}

Parents' perception and attitude towards their children's health and sports participation. All of the parents noted that they cared about their children's physical fitness. When they were asked about how to improve their children's health and fitness, they paid more attention to correcting their unhealthy habits, such as sleeping late and unbalanced diet instead of enhancing their physical activity. Just as they said in the interviews, "If he frees from illness and has a good appetite and enough sleep, he will be in good health. That is what we can do", and "There are physical teachers and physical activity in the school and my children have enough time to do exercise at school". Regarding how to balance the time between their children's academic work and exercise, as we had expected, exercise took a back seat to academic work for most parents. "Both of them are important, but if there is a conflict between academic work and exercise, studying is more important. Without good academic scores, he cannot get a decent job in the future".

Parents' role model of sports participation. The survey indicated that only $8.9 \%$ of the students reflected that their parents had physical exercise frequently, while $21.2 \%$ of them took exercise rarely and $30.1 \%$ of them never do any exercise (Zhang \& Li, 2014). This also has been proven in the interviews. Most parents stated that because of heavy work and lack of interest in sports, they seldom took exercise. "It is hard for me to do any exercise after a whole-day work", as one father said.

Parents' support and encouragement of sports participation. According to the results of the questionnaires, $58.9 \%$ of the students claimed that their parents encouraged them to engage in sports. Only $19.8 \%$ of the students chose their parents as their exercise partners. When talking about the sports facilities, $68.67 \%$ of the students complained that there was few sporting equipment at home, which was far from enough to meet their needs. As for support, most parents stated that they seldom did exercise with their children, and they noted that "My son/daughter prefers to play with their peers". Beside, lack of sports facilities in their local community has become a constraint, as $\mathbf{5 7 . 3 \%}$ of the students mentioned that "Sometimes, there is nowhere to do exercise". As a father interviewed reflected, “Once, I want to play badminton with my child, but there is no free court, and it is expensive to go the indoor stadium which charge 30 to 80 RMB per hour every week for me”. Furthermore, according to the survey, compared with rural students, urban students had more easy access to sports facilities.

Communication about students' physical status between school and family. There is an assessment of students' physical status in primary and middle schools annually, as an executive order issued by the Ministry of Education. Almost all the schools in the research have put the program into effect, but $50.7 \%$ of the teachers 
reflected that they never feed back the test results to the parents. Similarly, most parents stated that they did not know the physical performance of their children in school.

\section{Discussion and Conclusion}

The results from this study reflect that students do little physical exercise at home. There are two main reasons: 1 . Students have to do the homework and go to kinds of remedial classes arranged by their parents, they do not have enough time for exercise; and 2. Students are interested in watching TV and reading at home instead of going out for sports, they do not build the exercise habit yet. This represents that physical activity may not be considered as the priority by the parents and students, and there is a serious lack of knowledge and perceptions of the importance of physical education among the parents. Physical education, as an important part of all education (Ma, 2010), is not only the responsibility of school education, but also the responsibility of family education. Parents are important in influencing the way their child thinks and behaves. It is the parents who decide to push their child to study at home or do exercise outside. It is also the parents who guide their child to a sedentary lifestyle (such as staying indoors and watching TV) or a healthy lifestyle. All these choices are decided by parents' behaviors and beliefs.

The results of this study reflected that parents' perception and attitude towards their children's health and sports participation have certain limitations. Although they were concerned with their children's health and fitness, they equated good health with the mere absence of disease, and they pay more attention to provide them with a good diet. These opinions of "kitchen physic" are common among parents and grandparents in China. That is also why overweight and obese students can be seen popularly in schools. Although most of the parents know the significance of physical activity, good academic performance and decent jobs in the future are more important. As a result, the current family education in China is more concerned about intellectual education, and tries to transfer the responsibility of physical education to the school. This represents a serious lack of awareness of parents' responsibility in their children's physical education. It is obvious that the current philosophy of "exam results override all" has influenced them deeply. Parents have not realized either the importance of physical education or their potential capabilities of increasing physical activity levels of their children.

Much of the existing literature finds that parents are important role models for children's sports participation (Anderssen \& Wold, 1992; Kalakanis, Goldfield, Paluch, \& Epstein, 2001; Moore, Lombardi, White, Campbell, Oliveria, \& Ellison, 1991). More active parents are likely to have more active children. A study showed that children of two active parents were 5.8 times as likely to be active as children of two inactive parents (Moore et al., 1991). This means that children whose parents did not participate in sports were less likely to participate in exercise. However, in our survey, only $8.9 \%$ of the students reflected that their parents had physical exercise frequently. There is evidence to suggest that most parents do not act as role models to their children.

Children's sports participation should be supported and encouraged by their parents. Parents' support and encouragement are likely to enhance children's sporting interest, motivation, and enjoyment, and help them build the exercise habit and form their long-term passion to exercise, for example, investing their children's physical activity, buying family sporting equipment, supporting and encouraging them to the swimming, taekwondo, and the related classes instead of tutorial classes for English, mathematics, etc., driving their children to the sports places, going to watch their children frequently, and providing comments and rewards 
(Wheeler, 2012). The current study demonstrated that very little effort has been devoted by the parents to support their children for the physical activity. They cannot satisfy the fundamental needs for their children to do exercise actively, such as doing exercise with them and providing sporting equipment, not to mention providing positive comments and rewards. These also reflect the consumption conception of Chinese residents-the spending on sports is too little.

Schools and parents should share the responsibility of physical education of the students, and the basic stage of home-school cooperation to encourage and promote physical activity is information sharing. This means that schools should let parents know the real physical status of their children. Then the cooperation can go further in finding a solution to change low levels of activity participation. Here is a case in point. The Bureau of Education in Haidian District, Beijing, decided to assign physical homework to all the primary school students from January 1, 2014 (Yang \& Shi, 2014). There are a dozen of simple, flexible, and easy ways to operate athletic activities, such as doing push-ups, doing sit-ups, and doing rope skipping introduced in the homework. All the athletic activities have been divided into five sections, and the students were ordered to finish five athletic activities from different sections. Parents were ordered to record their children' performance and upload to the special websites from which the school could get the information at any time. The government also announced that the physical homework was not obligatory, but a method to enhance the physical activity of children with their parents (Yang \& Shi, 2014). Assigning physical homework aims to extend the school physical education to extracurricular activities and the daily life. It is helpful to change parents' perception and attitude towards physical education. Through this semi-mandatory homework, authorities and schools expect to change parents' attitudes that stress intellectual development of their children and neglect the family-based physical education. It is also a meaningful effort to make school leaders, teachers, and parents reach agreements on the countermeasures to promote students' fitness levels. This may contribute to fostering their good habits of physical exercise and also benefit to their overall development.

\section{References}

Anderssen, N., \& Wold, B. (1992). Parental and peer influences on leisure-time physical activity in young adolescents. Research Quarterly for Exercise and Sport, 63(4), 341-348.

Central Committee and the State Council. (2007). Advice on strengthening adolescent's physical education and enhancement of adolescent's physical fitness. Retrieved January 21, 2015, from http://news.xinhuanet.com/politics/2007-05/24/content_6148 322.html (In Chinese)

Gortmaker, S. L., Cheung, L. W. Y., Peterson, K. E., Chomitz, G., Cradle, J. H., Dart, H., ... Laird, N. (1999). Impact of a school-based interdisciplinary intervention on diet and physical activity among urban primary school children: Eat well and keep moving. Archives of Pediatrics \& Adolescent Medicine, 153(9), 975-983.

Kalakanis, L. E., Goldfield, G. S., Paluch, R. A., \& Epstein, L. H. (2001). Parental activity as a determinant of activity level and patterns of activity in obese children. Research Quarterly for Exercise and Sport, 72(3), 202-209.

Kremarik, F. A. (2000). Family affair: Children’s participation in sports. Canadian Social Trends, 58, 20-24.

Lv, Y. T. (2014). The 2013 result of school students' physical fitness and health surveillance in Jiangsu Province was published. Retrieved October 31, 2014, from http://www.jsenews.com/site/boot/newsmore_a2014051367618.html (In Chinese)

Ma, G. Z. (2010). Boling Zhang's physical education thought theory and its inspiration (Master's thesis, Hebei University).

Ministry of Education, General Administration of Sport, and Central Committee of the Communist Youth League. (2006). Advice on launching the nationwide "sunlight sport" campaign. Retrieved October 31, 2014, from http://www.moe.gov.cn/public files/business/htmlfiles/moe/moe_2530/201001/xxgk_80870.html (In Chinese)

Ministry of Education. (2010). The report of the physical fitness and health surveillance of Chinese school students. Retrieved January 21, 2015, from http://www.moe.edu.cn/publicfiles/business/htmlfiles/moe/s5948/201109/124202.html (In Chinese) 
Moore, L. L., Lombardi, D. A., White, M. J., Campbell, J. L., Oliveria, S. A., \& Ellison, R. C. (1991). Influence of parents' physical activity levels on activity levels of young children. The Journal of Pediatrics, 118(2), 215-219.

Norton, D. E., Froelicher, E. S., Waters, C. M., \& Carrieri-Kohlman, V. (2003). Parental influence on models of primary prevention of cardiovascular disease in children. European Journal of Cardiovascular Nursing, 2(4), 311-322.

Ren, S. C. (2013). The 2013 result of school students' physical fitness and health surveillance in Chongqing. Retrieved January 21, 2015, from http://cq.cqnews.net/html/2013-12/12/content_29017705.htm (In Chinese)

Su, T. (2014). The 2013 result of school students' physical fitness and health surveillance in Beijing reveals a troubling picture. Retrieved January 21, 2015, from http://www.jyb.cn/basc/xw/201404/t20140409_577417.html (In Chinese)

Timperio, A., Van Stralen, M., Brug, J., Bere, E., Chinapaw, M. J. M., Bourdeaudhuij, I. D., ... Velde, S. J. (2013). Direct and indirect associations between the family physical activity environment and sports participation among 10-12 year-old European children: Testing the EnRG framework in the ENERGY project. International Journal of Behavioral Nutrition and Physical Activity, 10, 15.

Trost, S. G., Sallis, J. F., Pate, R. R., Freedson, P. S., Taylor, W. C., \& Dowda, M. (2003). Evaluating a model of parental influence on youth physical activity. American Journal of Preventive Medicine, 25(4), 277-282.

Wang, S. M., Zou, J. L., Gifford, M., \& Dalal, K. (2014). Young students’ knowledge and perception of health and fitness: A study in Shanghai. China Health Education Journal, 73(1), 20-27.

Wheeler, S. (2012). The significance of family culture for sports participation. International Review for the Sociology of Sport, 47(2), 235-252.

Yang, C. G. (2012). Annual fitness monitoring for registered children will be carried out since 2013. Retrieved January 21, 2015, from http://www.jyb.cn/china/gnxw/201212/t20121225_522456.html (In Chinese)

Yang, X. Y., \& Shi, J. S. (2014). Haidian District, Beijing decide to assign physical homework in order to promote students' fitness and health. Retrieved October 31, 2014, from http://www.moe.edu.cn/publicfiles/business/htmlfiles/moe/s5147/2014 01/161657.html (In Chinese)

Zhang, L., \& Li, S. (2014). The issues and improvement of students' constitution in compulsory education based on the investigation in different regions of China. US-China Education Review B, 11, 839-845. 